\title{
KEPATUHAN MEDIKASI PENDERITA DIABETES MELLITUS \\ BERDASARKAN TEORI HEALTH BELIEF MODEL (HBM) \\ DI DIABETES CENTER KOTA TERNATE TAHUN 2017
}

\author{
Muhlisa $^{1}$, Amira BSA ${ }^{2}$ \\ 1 Politeknik Kesehatan Ternate, Jurusan Keperawatan \\ Diterima : 10 Oktober 2018, Disetujui : 26 Oktober 2018
}

\begin{abstract}
Background: Riskesdas in 2013, North Maluku Province is one of the areas in Indonesia with the prevalence of Diabetes Mellitus (DM) of 1.1\%. Data obtained from Diabetes Centre registers, from January to June 2017, the average patient DM visiting are 126 each month. Efforts have been made by the government in tackling the DM problem, but cases in Indonesia are still high. The study used the Health Belief Model (HBM) approach developed by Rosentock and Becker in 1974. HBM is a conceptual framework for understanding individual health behaviors. The purpose of this study is the identification of the perceptual factors of susceptibility, seriousness, benefits, obstacles and family support factors to compliance medication DM patients in the work area of Diabetes Center Ternate City in 2017. Method: using cross sectional approach with Sample amounted to 98 respondents. Instruments using Knowledge and Perception Questionnaire were analyzed using Chi Square test. Results: obtained are almost all respondents have perceptions of vulnerability, seriousness, benefits and obstacles are positive, as well as medication compliance, while for more family support is lacking. Conslusions: Statistical test result there is no correlation between perception of susceptibility, seriousness and benefit with medication compliance whereas perception of obstacles showed significant relationship.
\end{abstract}

Keywords: Diabetes Mellitus, Compliance, HBM Theory, Medication

\section{PENDAHULUAN}

Penyakit Diabetes mellitus (DM) yang umum dikenal sebagai kencing manis adalah penyakit metabolik dengan karakteristik hiperglikemia yang terjadi karena kelainan sekresi insulin, kerja insulin, atau kedua-duanya (American Diabetes Association, 2010). Penyakit ini akan tidak terkendali apabila dibiarkan dan dapat menimbulkan komplikasi lain yang membahayakan kesehatan (kemenkes RI, 2014). Indonesia merupakan negara keempat yang memiliki jumlah penderita DM terbanyak di dunia. Di Indonesia diperkirakan jumlah diabetisi mencapai 14 juta orang pada tahun 2006, dimana hanya $50 \%$ yang menyadari mengidap DM dan diantaranya sekitar $30 \%$ yang datang berobat secara teratur (WHO, 2008). Menurut laporan Riskesdas tahun 2013, Provinsi Maluku Utara merupakan salah satu wilayah di Indonesia dengan prevalensi penderita DM sebesar 1,1\% (Riskesdas 2013). Berdasarkan data awal yang didapatkan dari register DM di Diabetes Center, pada bulan Januari sampai dengan bulan Desember 2016 jumlah kunjungan penderita DM rata-rata 163 penderita setiap bulannya.

Upaya dan program telah dilakukan oleh pemerintah dalam 
menanggulangi masalah DM, namun kasus DM di Indonesia masih tinggi. Penelitian tahun 2008 oleh Litbang Kementerian Kesehatan RI menunjukan bahwa prevalensi nasional untuk DM sebesar 5,7\% (Soegondo, Soewondo, \& Subekti, 2009). Kemungkinan faktor penyebab adalah perilaku atau gaya hidup masyarakat yang mengarah ke faktor resiko DM seperti kurang aktivitas, diet tidak seimbang,dan merokok. Pendekatan secara individu dalam penanggulangan DM lebih diarahkan pada pendekatan terhadap keluarga karena keluarga merupakan penyedia pelayanan kesehatan utama bagi pasien yang mengalami penyakit kronik (Campell, 2000 dalam Friedman, Bowden, Jones, 2003). Hasil penelitian Haris, 2007 mengatakan bahwa ketidakpatuhan pasien DM dalam menjalani terapi merupakan salah satu penyebab ketidakberhasilan dalam penanganan diabetes. Selain itu dukungan keluarga merupakan salah satu dari faktor yang memiliki kontribusi yang cukup berarti dan sebagai faktor penguat yang mempengaruhi kepatuhan pasien diabetes melitus (Anggina et al, 2010).

Penelitian ini menggunakan pendekatan Health Belief Model (HBM) yang dikembangkan oleh Rosentock dan Becker tahun 1974. HBM merupakan kerangka konsep untuk memahami perilaku kesehatan individu. Glanz, Rimer, dan Viswanath (2008) mengemukakan bahwa diasumsikan bahwa HBM dapat menjelaskan alasan perilaku ketidakpatuahan penderita DM dalam melakukan terapi medikasi yang dianjurkan oleh tenaga kesehatan sebagai salah satu pengelolaan DM.

Tujuan dari penelitian ini adalah untuk mengidentifikasi faktor persepsi (individual perceptions): persepsi kerentanan, keseriusan, manfaat, dan hambatan terhadap kepatuhan medikasi penderita DM, faktor isyarat bertindak (cues to action): dukungan keluarga terhadap kepatuhan medikasi penderita DM, kepatuhan medikasi penderita DM dan hubungan karakteristik responden, persepsi individu, dan isyarat bertindak dengan kepatuhan medikasi penderita DM di wilayah kerja Diabetes Center Kota Ternate Tahun 2017.

\section{METODE PENELITIAN}

Penelitian ini adalah penelitian kuantitatif yang menggunakan desain deskriptif analitik dengan pendekatan cross sectional. Penelitian ini dilaksanakan di wilayah kerja Diabetes Center Kota Ternate. Populasil dalam penelitian ini adalah penderita diabetes melitus yang berkunjung ke Diabetes Center tahun 2017 dan diambil berdasarkan teknik purposive sampling dengan jumlah sampel 98 responden. Instrumen menggunakan Kuesioner Pengetahuan dan Persepsi dan dianalisis menggunakan uji Chi Square $\left(\mathrm{x}^{2}\right)$ dengan tingkat kemaknaan $\propto=0,05$ dan selanjutnya dilakukan analisis univariat dan bivariat.

\section{HASIL PENELITIAN}

Berdasarkan Tabel 1 dibawah ini menunjukkan hampir semua responden memiliki persepsi kerentanan yang positif $(53,1 \%)$, persepsi keseriusan positif $(58,2 \%)$, persepsi manfaat positif $(68,4 \%)$ dan persepsi hambatan yang positif $(75,5 \%)$. 
Tabel 1. Distribusi Responden Berdasarkan Persepsi

\begin{tabular}{lllll}
\hline No & variabel & kategori & Jml & \% \\
\hline 1 & Kerentanan & Positif & 52 & 53,1 \\
& & Negatif & 46 & 46,9 \\
\hline & Jumlah & & 98 & 100 \\
\hline 2 & Keseriusan & Positif & 57 & 58,2 \\
& & Negatif & 41 & 41,8 \\
\hline \multirow{3}{*}{3} & Jumlah & & 98 & 100 \\
\hline & Manfaat & Positif & 67 & 68,4 \\
& Negatif & 31 & 31,6 \\
\hline 4 & Jumlah & & 98 & 100 \\
\hline & Hambatan & Positif & 74 & 75,5 \\
& Negatif & 24 & 24,5 \\
\hline
\end{tabular}

Sumber: Data Primer

Berdasarkan Tabel 2 dibawah ini menunjukkan hampir semua responden memiliki dukungan keluarga yang baik hanya $40,8 \%$ sedangkan yang kurang lebih banyak yaitu 59,2\%.

Tabel 2. Distribusi responden berdasarkan Dukungan Keluarga

\begin{tabular}{lllll}
\hline No & Variabel & Kategori & Jml & \% \\
\hline 1 & Dukungan & Baik & 40 & 40,8 \\
& Keluarga & Kurang & 58 & 59,2 \\
\hline & Jumlah & & 98 & 100 \\
\hline
\end{tabular}

Sumber: Data Primer

Berdasarkan Tabel 3 menunjukkan hampir semua responden memiliki kepatuhan medikasi yaitu $75,5 \%$ dan yang tidak patuh yaitu $24,5 \%$.

Tabel 3. Distribusi responden berdasarkan Kepatuhan Medikasi

\begin{tabular}{lllll}
\hline No & variabel & Kategori & Jml & \% \\
\hline 1 & Kepatuhan & Patuh & 74 & 75,5 \\
& & Tidak patuh & 24 & 24,5 \\
\hline \multicolumn{3}{c}{ Jumlah } & 98 & 100 \\
\hline \multicolumn{2}{l}{ Sumber: Data Primer }
\end{tabular}

Berdasarkan Tabel 4 menunjukkan bahwa dukungan keluarga tidak memiliki hubungan yang bermakna dengan kepatuhan medikasi yang ditandai dengan nilai $\mathrm{p}=0.126$.
Tabel 4. Hubungan Persepsi dengan Dukungan Keluarga

\begin{tabular}{lllllll}
\hline Variabel & \multicolumn{2}{l}{ Kepatuhan } & \multicolumn{3}{c}{ Jumlah } \\
\cline { 2 - 7 } & \multicolumn{1}{l}{ Patuh } & \multicolumn{3}{l}{ Tidak patuh } & Jml & $\%$ \\
\cline { 2 - 7 } & Jml & $\%$ & Jml & $\%$ & & \\
\hline Dukungan & & & & & & \\
Keluarga & 27 & 27,5 & 13 & 13,3 & 40 & 40,8 \\
Baik & 47 & 48 & 11 & 11,2 & 58 & 59,2 \\
Kurang & 74 & 75,5 & 24 & 24,5 & 98 & 100 \\
\hline Jumlah & Uji Chi Square $\mathrm{p}=0.126$ & & & & \\
\hline Sumber: Data Primer
\end{tabular}

Berdasarkan Tabel 5 dibawah ini menunjukkan bahwa persepsi kerentanan, keseriusan dan manfaat tidak ada hubungan yang bermakna dengan kepatuhan medikasi ditandai dengan nilai $p=0.901$ untuk persepsi kerentanan, $\mathrm{p}=0.159$ untuk persepsi keseriusan dan $\mathrm{p}=0.085$ untuk persepsi manfaat, sedangkan persepsi hambatan berdasarkan uji statistik $\mathrm{p}=0.000$ menunjukkan ada hubungan yang bermakna.

Tabel 5. Hubungan Persepsi dengan Kepatuhan Medikasi

\begin{tabular}{|c|c|c|c|c|c|c|}
\hline \multirow[t]{3}{*}{ variabel } & \multicolumn{4}{|c|}{ Kepatuhan } & \multicolumn{2}{|c|}{ Jumlah } \\
\hline & \multicolumn{2}{|c|}{ Patuh } & \multicolumn{2}{|c|}{ Tidak patuh } & \multirow[t]{2}{*}{$\mathrm{Jml}$} & \multirow[t]{2}{*}{$\%$} \\
\hline & Jml & $\%$ & Jml & $\%$ & & \\
\hline \multicolumn{7}{|l|}{ Persepsi } \\
\hline Positif & 39 & 39,8 & 13 & 13,3 & 52 & 53 \\
\hline Negatif & 35 & 35,7 & 11 & 11,2 & 46 & 47 \\
\hline Jumlah & 74 & 75,5 & 24 & 24,5 & 98 & 100 \\
\hline \multicolumn{7}{|c|}{ Uji Chi Square $\mathrm{p}=0.901$} \\
\hline \multicolumn{7}{|c|}{ Persepsi } \\
\hline Positif & 46 & 47 & 11 & 11,2 & 57 & 58,2 \\
\hline Negatif & 28 & 28,5 & 13 & 13,3 & 41 & 41,8 \\
\hline Jumlah & 74 & 75,5 & 24 & 24,5 & 98 & 100 \\
\hline \multicolumn{7}{|c|}{ Uji Chi Square $\mathrm{p}=0.159$} \\
\hline \multicolumn{7}{|c|}{ Persepsi } \\
\hline Positif & 54 & 55,1 & 13 & 13,3 & 67 & 68,4 \\
\hline Negatif & 20 & 20,4 & 11 & 11,2 & 31 & 31,6 \\
\hline Jumlah & 74 & 75,5 & 24 & 24,5 & 98 & 100 \\
\hline \multicolumn{7}{|c|}{ Uji Chi Square $\mathrm{p}=0.085$} \\
\hline \multicolumn{7}{|l|}{ Persepsi } \\
\hline Positif & 74 & 75,5 & 0 & 0 & 74 & 75,5 \\
\hline Negatif & 0 & 0 & 24 & 24,5 & 24 & 24,5 \\
\hline Jumlah & 74 & 75,5 & 24 & 24,5 & 98 & 100 \\
\hline Uji Chi S & 0.000 & & & & & \\
\hline
\end{tabular}


Berdasarkan Tabel 6 berikut ini menunjukkan bahwa dukungan keluarga tidak memiliki hubungan yang bermakna dengan kepatuhan medikasi yang ditandai dengan nilai $\mathrm{p}=0.126$.

Tabel 6. Hubungan Persepsi dengan Dukungan Keluarga

\begin{tabular}{|c|c|c|c|c|c|c|}
\hline \multirow[t]{3}{*}{ Variabel } & \multicolumn{4}{|c|}{ Kepatuhan } & \multicolumn{2}{|c|}{ Jumlah } \\
\hline & \multicolumn{2}{|c|}{ Patuh } & \multicolumn{2}{|l|}{$\begin{array}{l}\text { Tidak } \\
\text { patuh }\end{array}$} & \multirow[t]{2}{*}{$\mathbf{J m l}$} & \multirow[t]{2}{*}{$\%$} \\
\hline & Jml & $\%$ & Jml & $\%$ & & \\
\hline \multicolumn{7}{|c|}{$\begin{array}{l}\text { Dukungan } \\
\text { Keluarga }\end{array}$} \\
\hline Baik & 27 & 27,5 & 13 & 13,3 & 40 & 40,8 \\
\hline Kurang & 47 & 48 & 11 & 11,2 & 58 & 59,2 \\
\hline Jumlah & 74 & 75,5 & 24 & 24,5 & 98 & 100 \\
\hline \multicolumn{7}{|c|}{ Uji Chi Square $\mathrm{p}=0.126$} \\
\hline
\end{tabular}

\section{PEMBAHASAN}

Hasil penelitian menunjukkan lebih banyak responden mempunyai persepsi kerentanan positif, artinya sebagian besar penderita DM merasakan adanya resiko atau bahaya yang bisa terjadi dengan penyakitnya. Notoatmodjo (2003) menyatakan agar seseorang bertindak untuk mengobati atau mencegah penyakitnya maka ia harus merasakan bahwa ia rentan (susceptible) terhadap penyakit tersebut. Hasil analisis menunjukkan tidak ada hubungan antara persepsi kerentanan dengan kepatuhan medikasi, yang sesuai dengan penelitian Ulum, dkk (2014), bahwa tidak ada hubungan antara persepsi kerentanan dengan kepatuhan medikasi di wilayah kerja Puskesmas Mulyorejo Surabaya dan Hasbi (2012) yang hasilnya menujukkan bahwa di wilayah kerja puskesmas Praya mempunyai persepsi kerentanan baik $(54.1 \%)$, artinya sebagian besar penderita DM merasakan adanya resiko atau bahaya yang bisa terjadi dengan penyakitnya namun hasil analisa statistik menunjukkan bahwa tidak ada hubungan antara persepsi kerentanan dengan kepatuhan penderita DM dalam melakukan olahraga, sedangkan hasil penelitian dari Puspita, dkk, 2017 menyatakan bahwa terdapat pengaruh persepsi kerentanan terhadap perilaku preventif hipertensi.

Hasil penelitian menunjukkan bahwa lebih banyak responden yang mempunyai persepsi keseriusan positif dan patuh dalam hal medikasi, namun hasil statistik tidak menunjukkan hubungan yang bermakna. Hasil tersebut tidak sejalan dengan konsep Health Belief Model (HBM) yang menyatakan bahwa persepsi keseriusan merupakan kepercayaan individu terhadap keseriusan penyakit yang dihadapi. Persepsi keseriusan yang dirasakan kemungkinan juga berbeda-beda pada setiap penderita DM. Hasil penelitian dari Adejoh, 2014 mendapatkan hubungan yang signifikan antara persepsi keseriusan dengan managemen dibetes. Kemungkinan faktor penyebab tingkat kepatuhan rendah dalam melakukan terapi medikasi adalah responden mempunyai persepsi sakit dalam konteks masyarakat, yaitu kondisi sakit adalah kondisi dimana individu tidak mampu melakukan aktivitas sehari-hari. Sehingga responden merasa sehat dan mengabaikan anjuran untuk mematuhi terapi medikasi sesuai anjuran medis.

Hasil penelitian menunjukkan bahwa lebih dari separuh responden memiliki persepsi manfaat positif, yang menyadari manfaat yang besar dari kepatuhan menjalani terapi medikasi terhadap penyakit yang diderita, namun hasil analisis menunjukkan bahwa tidak ada hubungan antara persepsi manfaat dengan kepatuhan medikasi. Hasil penelitian ini tidak sesuai dengan penelitian dari Ulum, dkk (2014) yang 
menyatakan bahwa ada hubungan antara persepsi manfaat dengan kepatuhan medikasi dan juga penelitian Hays \& Clark (1999) dalam Hasbi (2012) yang menyatakan bahwa ada hubungan persepsi manfaat penderita DM dengan perilaku olahraga pada usia lanjut African American di Mempis Amerika Serikat.

Hasil penelitian menunjukkan bahwa semua responden memiliki persepsi hambatan positif dan patuh dalam melakukan terapi medikasi, artinya respoden menganggap hambatan untuk patuh menjalankan terapi medikasi adalah kecil. Hasil uji statistik menunjukkan ada hubungan yang bermakna antara persepsi hambatan dengan kepatuhan medikasi. Hasil penelitian tersebut sesuai dengan penelitian dari Hasbi (2012) yang menunjukkan bahwa penderita DM di wilayah kerja puskesmas Praya memiliki persepsi hambatan baik (54\%), artinya penderita DM di puskesmas praya itu menganggap hambatan untuk melakukan olahraga itu adalah kecil, juga sejalan dengan penelitian Trost, Owen, Bauman dan Salis, (2002) dalam Hasbi (2012) bahwa persepsi hambatan mempunyai hubungan yang kuat tehadap kepatuhan dalam olahraga.

Hasil penelitian menunjukkan bahwa lebih banyak responden yang tidak mendapatkan dukungan keluarga dalam melaksanakan terapi medikasi dan hasil uji statistik juga menunjukkan tidak ada hubungan yang bermakna antara dukungan keluarga dengan kepatuhan medikasi. Hal tersebut tidak sesuai dengan Niven (2002) menyatakan bahwa dukungan keluarga dari anggota keluarga yang lain merupakan faktor penting dalam menjalankan program kepatuhan diit diabetes. Dukungan keluarga merupakan proses yang terjadi selama masa hidup dengan sifat dan tipe dukungan bervariasi meliputi dukungan emosional, dukungan informasional, dukungan instrumental dan dukungan penilaian (Friedman 2010). Dukungan tersebut membentuk satu kesatuan dukungan keluarga terutama bagi anggota keluarga yang mempunyai masalah kesehatan seperti Diabetes mellitus.

\section{KESIMPULAN DAN SARAN}

Berdasarkan hasil penelitian dapat disimpulkan bahwa faktor yang mempunyai hubungan bermakna dengan kepatuhan medikasi adalah persepsi hambatan, sedangkan persepsi kerentanan, keseriusan, manfaat dan dukungan keluarga tidak memiliki hubungan yang bermakna dengan kepatuhan medikasi.

\section{DAFTAR RUJUKAN}

Adejoh Ojima, S, 2014. Diabetes Knowledge, Health Belief and Diabetes management Among the Igala, Nigeria. SAGE Open

Bare BG., Smeltzer SC. 2001. Buku Ajar Keperawatan Medikal Bedah. Jakarta: EGC.

Dinas Kesehatan Kota Ternate, 2016. Profil Kerja UPTD Diabetes Center Tahun 2016. Dinkes Kota Ternate

Friedman, M. M., Bowden, V. R., \& Jones, E. G. (2003). Family Nursing: Research, Theory, \& Practice. New Jersey: Pearson Education, Inc.

Glanz K., Rimer B.K., Viswanath. (2008). Health Behavior and Health Education: Theory, Research, and Practice. Jossey-Bass: Francisco.

Haris, M.A. (2007). The Family's Involment in Diabetes Care and the Problem of Helping. 
Hasbi, M, 2012, Analisis faktor yang berhubungan dengan kepatuhan penderita diabetes melitus dalam melakukan olahraga di wilayah kerja puskesmas praya lombok tengah. Depok: Tesis Program Studi Magister Ilmu Keperawatan Peminatan Keperawatan Komunitas Universitas Indonesia.

Niven, N, 2002, Psikologi Kesehatan, Pengantar untuk perawat dan Profesional Kesehatan Lain, Jakarta: Buku Kedokteran EGC

Notoatmodjo S. 2013. Ilmu Perilaku Kesehatan. Jakarta: Rineka Cipta

PERKENI. 2011. Konsensus Pengelolaan dan Pencegahan Diabetes Melitus Tipe 2 di Indonesia 2011. Jakarta: PERKENI

Puspita, Tamtomo, Indarto, 2017. Health Belief Model for The Analysis of Factors Affecting Hypertension Preventive Behavior among Adolescents in Surakarta. Journal of Health Promotion and Behaviour

Price, S. A. dan Wilson, L. M. 2006.
Patofisiologi : Konsep Klinis Proses- Proses Penyakit, Edisi 6, Volume 1. Jakarta: EGC.

Rochmah W. 2006. Diabetes Melitus Pada Usia Lanjut. Jakarta: Depertemen Ilmu Penyakit Dalam Fakultas Kedokteran Universitas Indonesia

Smet, Bart. 1994. Psikologi Kesehatan. Penerbit PT Grasindo Anggota IKAPI, Jakarta

Soegondo, S., 2009. Prinsip Penanganan Diabetes, Insulin dan Obat Hipoglikemik Oral. Dalam : Soegondo, S., Soewondo,P., Subekti, I., Penatalaksanaan Diabetes Melitus Terpadu. Fakultas Kedokteran Universitas Indonesia, Jakarta

Ulum, 2014. Kepatuhan Medikasi Penderita Diabetes Mellitus Tipe 2 Berdasarkan Teori Health Belief Model (HBM) di Wilayah Kerja Puskesmas Mulyorejo Surabaya. Retrieved from journal.unair.ac.id/ 